Elsevier required licence: (C) <2017>. This manuscript version is made available under the CC-BY-NC-ND 4.0 license http://creativecommons.org/licenses/bync-nd/4.0/ 


\title{
Characteristics of electron transport chain and affecting factors for thiosulfate-driven perchlorate reduction
}

\author{
Chao Zhang ${ }^{\mathrm{a}, \mathrm{b}}$, Jianbo Guo ${ }^{\mathrm{a}, \mathrm{b}, *}$, Jing Lian ${ }^{\mathrm{b}}$, Caicai Lu ${ }^{\mathrm{a}}$, Huu Hao $\mathrm{Ngo}^{\mathrm{c}}$, Wenshan Guo ${ }^{\mathrm{c}}$, \\ Yuanyuan Song ${ }^{\mathrm{a}}$, Yankai Guo ${ }^{\mathrm{b}}$ \\ ${ }^{a}$ Tianjin Key Laboratory of Aquatic Science and Technology, School of Environmental and Municipal \\ Engineering, Tianjin Chengjian University, Jinjing Road 26\#, Tianjin 300384, PR China \\ ${ }^{b}$ School of Environmental Science and Engineering \& Pollution Prevention Biotechnology Laboratory of \\ Hebei Province, Hebei University of Science and Technology, Yuhua East Road 70\#, Shijiazhuang \\ 050018, PR China \\ ${ }^{c}$ Centre for Technology in Water and Wastewater, School of Civil and Environmental Engineering, \\ University of Technology Sydney, Ultimo, NSW 2007, Australia \\ * Corresponding author. E-mail address: jianbguo@163.com (J. Guo).
}

\begin{abstract}
The mechanism for perchlorate reduction was investigated using thiosulfate-driven (T-driven) perchlorate reduction bacteria. The influences of various environmental conditions on perchlorate reduction, including $\mathrm{pH}$, temperature and electron acceptors were examined. The maximum perchlorate removal rate was observed at $\mathrm{pH} 7.5$ and $40{ }^{\circ} \mathrm{C}$. Perchlorate reduction was delayed due to the coexistence of perchlorate-chlorate and perchlorate-nitrate. The mechanism of the T-driven perchlorate reduction electron transport chain (ETC) was also investigated by utilizing different inhibitors. The results were as follows: firstly, the NADH dehydrogenase was not involved in the ETC; secondly, the FAD dehydrogenase and quinone loop participated in the ETC; and thirdly, cytochrome oxidase was the main pathway in the ETC. Meanwhile, microbial consortium structure analysis indicated that Sulfurovum which can oxidize sulfur compounds coupled to the reduction of nitrate or perchlorate was the primary bacterium in the T-driven and sulfur-driven consortium. This study generates a better understanding of the mechanism of T-driven perchlorate reduction.
\end{abstract}

Keywords: Perchlorate reduction; Thiosulfate; Electron acceptor; Electron transport chain; Microbial consortium structure

\section{Introduction}

Perchlorate is one of the major inorganic contaminants in surface and groundwater and is commercially produced from solid rocket fuel propellants, explosives, and pyrotechnics (Wan et al., 2016; Xu et al., 2015; Butler et al., 2010). The primary health problem caused by perchlorate is its disruption of the thyroid function by interfering with iodine uptake, thus inhibiting thyroid hormone production (Wang et al., 2014; Ju et al., 2008). In the United States, perchlorate has been detected at more than 150 sites in more than 38 states (Boles et al., 2012). As a result, California, Massachusetts, and Maryland have established their own individual standards of perchlorate levels between 1 and $6 \mu \mathrm{g} \mathrm{L}^{-1}$ (Boles et al., 2012). Perchlorate has also been detected at many locations throughout China (Ye et al., 2013; Shi et al., 2007). Shi et al. (2007) discovered that the concentrations of perchlorate in sewage sludge, rice, bottled drinking water and milk ranged from 
0.56 to $379.90 \mu \mathrm{g} \mathrm{kg}^{-1}, 0.16$ to $4.88 \mu \mathrm{g} \mathrm{kg}^{-1}, 0.04$ to $2.01 \mu \mathrm{g} \mathrm{L}^{-1}$ and 0.30 to $9.10 \mu \mathrm{g} \mathrm{L}^{-1}$, respectively. These results confirmed that perchlorate contamination is now widespread in China. Therefore, determining a strategy to remove perchlorate contamination is important for protecting the environment.

Strategies for treating perchlorate-contaminated waters include physicochemical methods and biological methods (Baidas et al., 2011; Zhao et al., 2011; Xu and Logan, 2003). Biological methods are a promising alternative to physicochemical approaches because of the low operational cost associated with good performance for perchlorate remediation (Xu et al., 2015; Gao et al., 2016; Xu and Logan, 2003).

Biological reduction relies on either heterotrophic or autotrophic microorganisms. Heterotrophic reduction of perchlorate has been done using organic matter as electron donors, including acetate, lactate, and ethanol (Anupama et al., 2015; Xu et al., 2015; Xu and Logan, 2003). However, the residual organic substrate in the effluent can stimulate microbial growth in water distribution systems and contribute to the formation of potentially toxic trihalomethanes during disinfection by chlorination (Gao et al., 2016). Autotrophic reduction of perchlorate has been undertaken using inorganic matter as electron donors, including hydrogen (London et al., 2011; Nerenberg et al., 2008, 2006), reduced iron (Son et al., 2006), and sulfur compounds (Gao et al., 2016; Boles et al., 2012; Ju et al., 2008, 2007) to overcome this problem.

Researchers have investigated sulfur compounds $\left(\mathrm{S}^{0}, \mathrm{H}_{2} \mathrm{~S}\right.$ and $\mathrm{S}_{2} \mathrm{O}_{3}{ }^{2-}$ ) as electron donors (Boles et al., 2012; Ju et al., 2008, 2007). Because granular sulfur is insoluble in water, it has emerged as a novel electron donor for packed bed reactors. However, for suspended sludge, thiosulfate is a better electron donor than granular sulfur (Mora et al., 2015, 2014; Ju et al., 2008). Thiosulfate serving as an electron donor for autotrophic perchlorate reduction has been reported in some studies (Liebensteiner et al., 2015; Ju et al., 2008). Ju et al. (2008) evaluated various inoculum sources in terms of their ability to utilize thiosulfate as an electron donor for perchlorate reduction. The expected stoichiometry of the reaction is as follows:

$$
\mathrm{S}_{2} \mathrm{O}_{3}^{2-}+\mathrm{ClO}_{4}^{-}+\mathrm{H}_{2} \mathrm{O} \rightarrow 2 \mathrm{SO}_{4}^{2-}+\mathrm{Cl}^{-}+2 \mathrm{H}^{+}
$$

However, few studies have examined environmental factors including temperature, $\mathrm{pH}$ value and co-existing electron acceptors (e.g., nitrate and chlorate) on thiosulfate-driven (T-driven) perchlorate reduction. Electron transport inhibitors, which could block certain parts of the electron transfer chain, were used to analyze electron carrier participation in related biological processes (Wang et al., 2016; Lian et al., 2016; Hong et al., 2007; Woźnica et al., 2003). However, only a few studies have examined the electron transport chain (ETC) mechanism and characteristics for T-driven perchlorate reduction. Madigan et al. (2011) concluded that the electron transport pathways of $\mathrm{S}^{0}$ and $\mathrm{S}_{2} \mathrm{O}_{3}{ }^{2-}$ as electron donors were similar. It should be noted that the relationship between T-driven perchlorate reduction and sulfur-driven (S-driven) perchlorate reduction has not yet been described.

The main objectives of this research were to: (1) investigate the influence of various environmental conditions on T-driven perchlorate reduction bacteria (PCRB); (2) gain further insights into the 
perchlorate reduction process using inhibitors of the ETC; and (3) analyze the variation in the microbial consortium structure among original activated sludge, T-driven PCRB and S-driven PCRB.

\section{Materials and methods}

\subsection{Bacteria inoculation and acclimation}

Activated sludge was collected from a local municipal wastewater treatment plant (Qiaoxi District, Shijiazhuang, China). This sludge was enriched in a basal medium containing $\mathrm{ClO}_{4}{ }^{-}$and $\mathrm{S}_{2} \mathrm{O}_{3}{ }^{2-}$. The composition of the basal medium was as follows $\left(\mathrm{g} \mathrm{L}^{-1}\right): 0.25 \mathrm{~K}_{2} \mathrm{HPO}_{4} \cdot 3 \mathrm{H}_{2} \mathrm{O}, 1.50$ $\mathrm{NaHCO}_{3} \cdot \mathrm{H}_{2} \mathrm{O}, 0.15 \mathrm{NH}_{4} \mathrm{Cl}, 0.11 \mathrm{NaClO}_{4}$ and $0.75 \mathrm{Na}_{2} \mathrm{~S}_{2} \mathrm{O}_{3}$. A microelement solution $\left(1.0 \mathrm{~mL} \mathrm{~L}^{-1}\right)$ was added to the medium, which contained the following in $\mathrm{g} \mathrm{L}^{-1}: 0.50 \mathrm{EDTA}, 0.50 \mathrm{MnSO}_{4} \cdot \mathrm{H}_{2} \mathrm{O}$, $0.10 \mathrm{FeSO}_{4} \cdot 7 \mathrm{H}_{2} \mathrm{O}, 0.10 \mathrm{CaCl}_{2}$ (anhydrous), $0.10 \mathrm{ZnSO}_{4} \cdot 7 \mathrm{H}_{2} \mathrm{O}, 0.01 \mathrm{CuSO}_{4} \cdot 5 \mathrm{H}_{2} \mathrm{O}, 0.01$ $\mathrm{Na}_{2} \mathrm{MoO}_{4} \cdot 2 \mathrm{H}_{2} \mathrm{O}, 0.01 \mathrm{Na}_{2} \mathrm{WO}_{4} \cdot 2 \mathrm{H}_{2} \mathrm{O}$ and $0.02 \mathrm{NiCl}_{2} \cdot 6 \mathrm{H}_{2} \mathrm{O}$.

The seed was acclimated in a $2 \mathrm{~L}$ sealed container consisting $1 \mathrm{~L}$ of sludge and $1 \mathrm{~L}$ of basal medium at $35^{\circ} \mathrm{C}$ with shaking. The initial $\mathrm{ClO}_{4}{ }^{-}$concentration was $120 \mathrm{mg} \mathrm{L}^{-1}$, and the $\mathrm{S}_{2} \mathrm{O}_{3}{ }^{2-}$ content was $135 \mathrm{mg} \mathrm{L}^{-1}$, which was equal to the theoretical requirement for the complete reduction of $\mathrm{ClO}_{4}^{-}$ according to reaction (1). When $\mathrm{ClO}_{4}{ }^{-}$was depleted, $500 \mathrm{~mL}$ fresh medium (rate of displacement being $25 \%$ ) was added to the container for the next acclimation cycle (one day for a cycle). The procedure for the analysis of volatile suspended solids (VSS) is illustrated in Fig. S1.

\subsection{Chemicals}

The inhibitors included cupricchloride $\left(\mathrm{CuCl}_{2}\right)$, Rotenone, quinacrine dihydrochloride (QDH), dicumarol, sodium azide $\left(\mathrm{NaN}_{3}\right)$, and $\mathrm{N}_{2} \mathrm{~N}^{\prime}$-Dicyclohexylcarbodiimide (DCCD). These inhibitors were purchased from Sigma-Aldrich (St. Louis, MO). All other chemical reagents were of analytical grade and purchased from Xiandai Ltd. (Shijiazhuang, China).

\subsection{Experimental setup}

The acclimation process was repeated for 70 cycles. Stable perchlorate reduction rate and biomass were observed for 30 cycles. An uninoculated flask containing $\mathrm{ClO}_{4}{ }^{-}, \mathrm{S}_{2} \mathrm{O}_{3}{ }^{2-}$ and the basal medium served as the control for abiotic reactions. Autoclaved control and no $\mathrm{S}_{2} \mathrm{O}_{3}{ }^{2-}$ control were run in parallel, and the results are illustrated in Fig. S2. All experiments were conducted in $250 \mathrm{~mL}$ glass flasks containing $100 \mathrm{~mL}$ of acclimated sludge $\left(7.1 \pm 0.2 \mathrm{~g} \mathrm{VSS} \mathrm{L}^{-1}\right)$ and $150 \mathrm{~mL}$ of fresh basal medium. All of the flasks were sealed at a temperature of $35^{\circ} \mathrm{C}$ and purged with pure $\mathrm{N}_{2}$ to maintain anaerobic conditions. Each flask was sampled at regular intervals for the measurement of $\mathrm{ClO}_{4}^{-}$, $\mathrm{Cl}^{-}, \mathrm{S}_{2} \mathrm{O}_{3}{ }^{2-}$, and $\mathrm{SO}_{4}{ }^{2-}$. The specific molar yield of $\mathrm{Cl}^{-}$and $\mathrm{SO}_{4}{ }^{2-}$ per $\mathrm{M} \mathrm{ClO}_{4}{ }^{-}$consumed, which was linked to $\mathrm{S}_{2} \mathrm{O}_{3}{ }^{2-}$ oxidation, is shown in Table $\mathrm{S} 1$. Each group was tested in triplicate. The biomass concentration was considered constant throughout each test because the differences in the VSS values before and after each experiment were detected within 5\%.

\subsubsection{Effect of $\mathrm{pH}$ and temperature on PCRB}


To evaluate the effect of $\mathrm{pH}$ and temperature, $\mathrm{T}$-driven PCRB was examined at $\mathrm{pH}$ values ranging from 5.0 to 8.5 and temperatures from $20^{\circ} \mathrm{C}$ to $60^{\circ} \mathrm{C}$. The tested sludge was obtained from the 32nd acclimation cycle. The medium containing $80 \mathrm{mg} \mathrm{L}^{-1} \mathrm{ClO}_{4}{ }^{-}$and $120 \mathrm{mg} \mathrm{L}^{-1} \mathrm{~S}_{2} \mathrm{O}_{3}{ }^{2-}$ was adjusted to different $\mathrm{pH}$ values $(5.0,5.5,6.0,6.5,7.0,7.5,8.0$, and 8.5$)$ with $1.0 \mathrm{M} \mathrm{HCl}$ or $1.0 \mathrm{M}$ $\mathrm{NaOH}$. In the temperature experiment, cultures were grown at $20^{\circ} \mathrm{C}, 30^{\circ} \mathrm{C}, 40{ }^{\circ} \mathrm{C}, 50{ }^{\circ} \mathrm{C}$ and $60{ }^{\circ} \mathrm{C}$.

\subsubsection{Kinetics experiments}

To evaluate the effect of chlorate or perchlorate concentration, T-driven PCRB was examined at chlorate or perchlorate concentrations ranging from $20 \mathrm{mg} \mathrm{L}^{-1}$ to $120 \mathrm{mg} \mathrm{L}^{-1}$. The tested sludge was derived from the 38 th acclimation cycle. The medium contained $150 \mathrm{mg} \mathrm{L}^{-1} \mathrm{~S}_{2} \mathrm{O}_{3}{ }^{2-}$. The chlorate or perchlorate concentrations were 20,40,60,80, 100 and $120 \mathrm{mg} \mathrm{L}^{-1}$. The kinetics of perchlorate reduction by T-driven PCRB can be described by the Monod equation (Eq. (1)):

$$
-\frac{d S}{d t}=v=\frac{q_{\max } X S}{K_{S}+S}
$$

$\mathrm{S}$ is the (per)chlorate concentration $\left(\mathrm{mg} \mathrm{L}^{-1}\right)$; $\mathrm{v}$ is the removal rate of (per)chlorate $\left(\mathrm{mg} \mathrm{ClO}{ }_{4}^{-} \mathrm{L}^{-1}\right.$ $\left.\mathrm{h}^{-1}\right)$; $\mathrm{X}$ is microbial concentration $\left(\mathrm{mg} \mathrm{L}^{-1}\right)$; $\mathrm{q}_{\max }$ is the maximum specific substrate degradation rate $\left(\mathrm{mg} \mathrm{ClO}_{4}^{-} \mathrm{g}-\mathrm{VSS}^{-1} \mathrm{~h}^{-1}\right) ; \mathrm{K}_{\mathrm{s}}$ is the half saturation constant.

\subsubsection{Effect of co-existing nitrate and chlorate on PCRB}

Two pairs of electron-acceptor systems (perchlorate-chlorate and perchlorate-nitrate) were tested for their potential to receive the electrons from thiosulfate. The tested sludge originated from the 44th acclimation cycle. The concentrations of $\mathrm{NO}_{3}{ }^{-}$and $\mathrm{ClO}_{3}{ }^{-}$varied from 0 to $100 \mathrm{mg} \mathrm{L}^{-1}$ while the initial concentrations of $\mathrm{ClO}_{4}{ }^{-}$and $\mathrm{S}_{2} \mathrm{O}_{3}{ }^{2-}$ were set at 80 and $200 \mathrm{mg} \mathrm{L}^{-1}$, respectively. The $\mathrm{NO}_{3}{ }^{-}$and $\mathrm{ClO}_{3}{ }^{-}$concentrations were $0,20,40,60,80$ and $100 \mathrm{mg} \mathrm{L}^{-1}$. Thirty-six flasks were sealed and shaken once every $30 \mathrm{~min}$.

\subsubsection{Effect of electron transport inhibitors on perchlorate reduction}

The tested sludge was from the 44th acclimation cycle and the inhibition sites of the inhibitors are shown in Table $\mathrm{S} 2$. The initial perchlorate and $\mathrm{S}_{2} \mathrm{O}_{3}{ }^{2-}$ concentrations were fixed at 80 and $120 \mathrm{mg} \mathrm{L}^{-1}$, respectively, and the inhibitors concentrations ranged from 0 to $400 \mu \mathrm{M} \mathrm{L}^{-1}$ (Lian et al., 2016; Wang et al., 2016; Xi et al., 2013).

\subsubsection{Change in the microbial consortium structure}

The different consortium structures of the original activated sludge, T-driven PCRB, and S-driven PCRB were analyzed by $16 \mathrm{~S}$ DNA metagenomic sequencing. A T-driven PCRB sample was collected from the inoculated sludge, which was acclimated by thiosulfate after the 38th acclimation cycle. An S-driven PCRB sample was collected from the inoculated sludge, which was acclimated by sulfur after the $200^{\text {th }}$ cycle, and the acclimation procedure was similar to that for Tdriven PCRB.

\subsection{Experimental setup}


Samples $(10 \mathrm{~mL})$ were transferred from each flask for perchlorate measurement. The samples were centrifuged at $10,000 \mathrm{~g}$ for $10 \mathrm{~min}$. The supernatant was then filtered with a $0.22 \mu \mathrm{m}$ filter membrane (nylon membrane). Concentrations of $\mathrm{ClO}_{4}^{-}, \mathrm{ClO}_{3}{ }^{-}, \mathrm{Cl}^{-}, \mathrm{SO}_{4}{ }^{2-}$, and $\mathrm{NO}_{3}{ }^{-}$were analyzed using an ion chromatograph (Dionex 1100) fitted with a Dionex IonPac AS 20 analytical column $(4 \times 250 \mathrm{~mm})$ and a Dionex AG 20 guard column $(4 \times 50 \mathrm{~mm})$. An eluent gradient concentration $(\mathrm{KOH})$ from 15 to $40 \mathrm{mM}$ was utilized $(0 \mathrm{~min}-10 \mathrm{~min}$ with $15 \mathrm{mM}$ and $10 \mathrm{~min}-$ $21 \mathrm{~min}$ with $40 \mathrm{mM}$ ). And error in the parameter estimates was determined by approximating $95 \%$ joint confidence limits for all experimental scenarios (With the error bars representing confidence intervals). The $\mathrm{pH}$ was determined using $\mathrm{pH}$ meters (520A, Thermo Orion, USA), respectively. The volatile suspended solids (VSS) were measured using standard methods (APHA, 1998). Then the microbial consortium structure was examined using 16S DNA metagenomic sequencing (Sangon Biotech Ltd, Shanghai China). Genomic DNA was extracted using a Qubit2.0 DNA Assay Kit. The V3-V4 region of 16S rRNA genes was amplified using bacterial primers $341 \mathrm{~F}$ (CCCTACACGACGCTCTTCCGATCTG CCTACGGGNGGCWGCAG) and 805R (GACTGGAGTTCCTTGGCACCCGAGAATTCCAGACTACHVGGGTATCTAAT CC). Furthermore the sequencing data analysis methods followed the method described by OntiverosValencia et al. (2013).

\section{Results and discussion}

\subsection{Effect of $\mathrm{pH}$ and temperature}

The $\mathrm{pH}$ and temperature could significantly affect the electron transfer reactions of $\mathrm{ClO}_{4}{ }^{-}$to $\mathrm{ClO}_{3}{ }^{-}$ and $\mathrm{ClO}_{3}{ }^{-}$to $\mathrm{ClO}_{2}{ }^{-}$(Zhu et al., 2016; Song et al., 2015; Wu et al., 2008). To evaluate the effect of $\mathrm{pH}$ and temperature, the T-driven PCRB was examined at $\mathrm{pH}$ values ranging from 5.0 to 8.5 (Fig. 1a) and at temperatures ranging from $20^{\circ} \mathrm{C}$ to $60^{\circ} \mathrm{C}$ (Fig. 1b).

As indicated in Fig. 1a, the promising perchlorate removal efficiencies were obtained at $\mathrm{pH} 7.5$, and the perchlorate removal efficiencies within $6 \mathrm{~h}$ were $63 \%, 76 \%, 82 \%, 91 \%, 97 \%, 100 \%, 94 \%$ and $70 \%$ with $\mathrm{pH}$ values of $5.0,6.0,6.5,7.0,7.5,8.0$ and 8.5 , respectively. The maximum specific perchlorate degradation rate $\left(\mathrm{q}_{\max }\right)\left(2.22 \mathrm{mg} \mathrm{ClO}_{4}^{-} \mathrm{g}^{-} \mathrm{VSS}^{-1} \mathrm{~h}^{-1}\right)$ was also obtained at $\mathrm{pH} 7.5$ (Fig. 1a). This outcome has been documented in many studies (Zhu et al., 2016; Song et al., 2015; $\mathrm{Wu}$ et al., 2008). The $\mathrm{pH}$ effect on the perchlorate reduction is that variations in $\mathrm{pH}$ change the ionic form of the acid and base groups on the active sites of an enzyme (Xu et al., 2015).

As shown in Fig. 1b, the maximum specific perchlorate degradation rate was $2.26 \mathrm{mg} \mathrm{ClO}_{4}{ }^{-} \mathrm{g}-$ $\mathrm{VSS}^{-1} \mathrm{~h}^{-1}$ at $40{ }^{\circ} \mathrm{C}$, and perchlorate could be completely reduced within $6 \mathrm{~h}$. Subsequently, the specific perchlorate degradation rate decreased remarkably when the temperature increased to $60{ }^{\circ} \mathrm{C}$. The perchlorate removal efficiencies within $6 \mathrm{~h}$ were $55 \%, 89 \%, 98 \%, 48 \%$ and $36 \%$ at $20^{\circ} \mathrm{C}, 30^{\circ} \mathrm{C}, 40^{\circ} \mathrm{C}, 50^{\circ} \mathrm{C}$ and $60^{\circ} \mathrm{C}$, respectively (Fig. 1b). Microbial activity is significantly affected by temperature and the optimal temperature for perchlorate reduction was approximately $37^{\circ} \mathrm{C}$, which was consistent with Zhu et al. (2016).
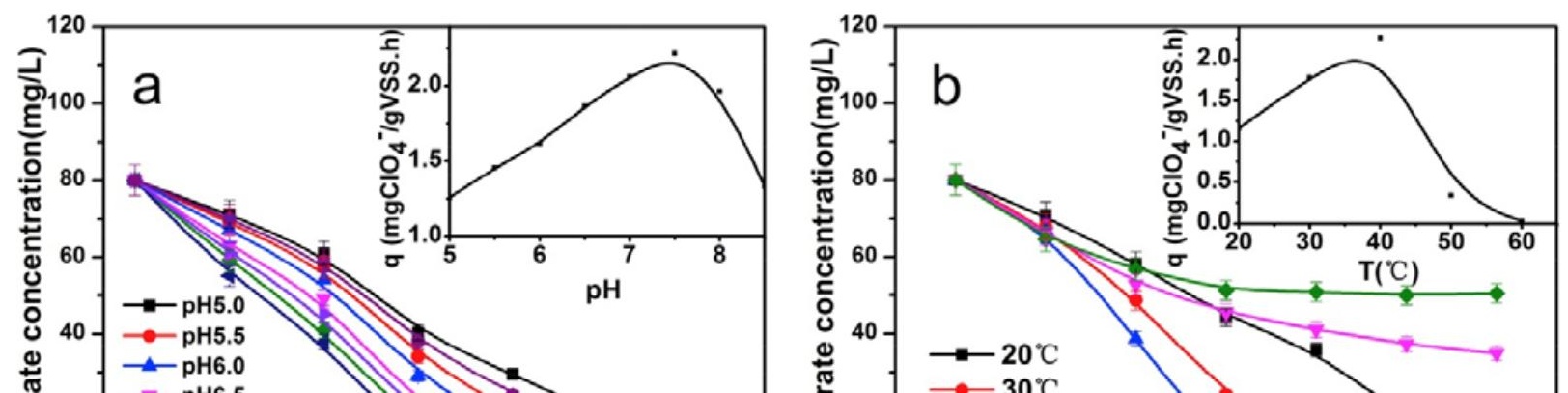
Fig. 1. Effect of different (a) $\mathrm{pH}$ values and (b) temperatures on perchlorate reduction (Conditions: biomass $=7.1 \pm 0.2 \mathrm{~g} \mathrm{VSS} \mathrm{L}^{-1}$; perchlorate concentration $=80 \mathrm{mg} / \mathrm{L}$; thiosulfate concentration $=120 \mathrm{mg} / \mathrm{L}$; temperature of $\mathrm{pH}$ experiment $=35^{\circ} \mathrm{C} ; \mathrm{pH}$ of temperature experiment $=7.0 \pm 0.2$ ).

\subsection{Chlorate and perchlorate reduction kinetics}

To evaluate the different removal rates between perchlorate and chlorate, the amount of chlorate or perchlorate removal over time at different perchlorate concentrations (Fig. 2a) and chlorate concentrations (Fig. 2b) was measured.
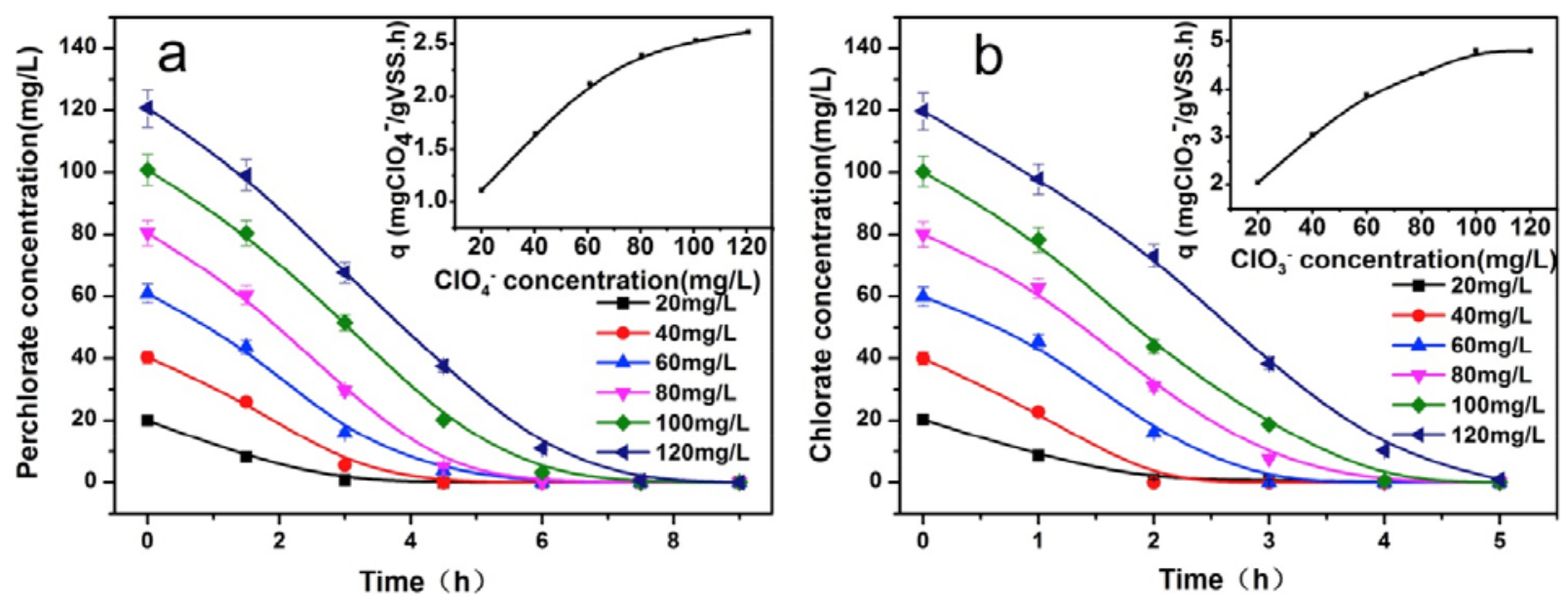

Fig. 2. Effect of different initial (a) chlorate and (b) perchlorate concentrations on chlorate or perchlorate reduction (Conditions: biomass $=7.1 \pm 0.2 \mathrm{~g} \mathrm{VSS} \mathrm{L}^{-1}$; thiosulfate concentration $=150 \mathrm{mg} / \mathrm{L}$; temperature $=35^{\circ} \mathrm{C} ; \mathrm{pH}=7.0 \pm 0.2$ ).

As indicated in Fig. 2, perchlorate (20-120 mg L $\mathrm{m}^{-1}$ ) was completely reduced within $8 \mathrm{~h}$ (Fig. 2a) and chlorate (20-120 $\mathrm{mg} \mathrm{L}^{-1}$ ) was completely reduced within $5 \mathrm{~h}$ (Fig. 2b). To facilitate a better comparison, the specific perchlorate and chlorate degradation rates were calculated. The specific chlorate and perchlorate degradation rate increased with the increase of initial chlorate and perchlorate concentrations, respectively. The specific perchlorate degradation rate was $2.61 \mathrm{mg}$ $\mathrm{ClO}_{4}{ }^{-} \mathrm{g}-\mathrm{VSS}^{-1} \mathrm{~h}^{-1}$ at the initial concentration of $120 \mathrm{mg} \mathrm{L}^{-1}$ which was 2.36 times for the initial concentration of $20 \mathrm{mg} \mathrm{L}^{-1}$ (Fig. 2a). And the specific perchlorate removal rate was much higher than most of the values reported in previous studies (Table S3). The specific chlorate degradation

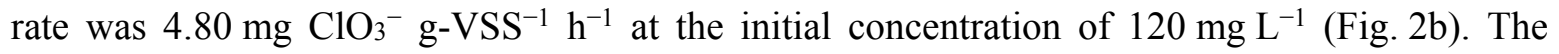


relationship between chlorate or perchlorate concentrations and the removal rate was well fitted by the Monod model (Fig. S3). According to Eq. (1), the perchlorate kinetic parameters qmax and Ks

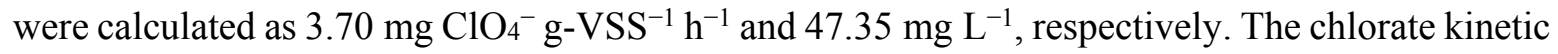

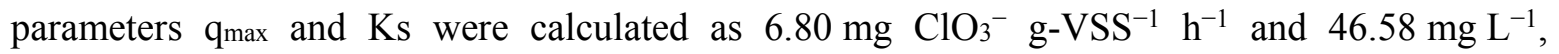
respectively. The high $\mathrm{q}_{\max }$ and Ks values implied the high removal rate and high tolerance against highly concentrated chlorate or perchlorate. Hence, the chlorate removal rate was higher than the perchlorate removal rate, and the tolerance against highly concentrated chlorate or perchlorate was similar. Similar results were also observed in the study by Bardiya and Bae (2011), which utilized chlorate in preference to perchlorate. Hence, the transformation of perchlorate into chlorate was the rate-determining step for the T-driven perchlorate reduction.

\subsection{Multiple electron acceptors}

Nitrate and chlorate are often the concomitant pollutants in perchlorate wastewater, and these inorganic electron acceptors can be reduced by most PCRB (Bardiya and Bae, 2011; Zhao et al., 2011; Choi and Silverstein, 2008). These co-existing electron acceptors may regulate, hinder or completely inhibit the perchlorate reduction (Xu et al., 2015; Bardiya and Bae, 2011; Zhao et al., 2011). Interactions between perchlorate and other co-existing electron acceptors were evaluated in this study.

\subsubsection{Effect of chlorate on perchlorate reduction}

The coexistence of perchlorate-chlorate experiment showed that chlorate significantly inhibited perchlorate reduction (Fig. 3). Compared with the control ( $0 \mathrm{mg} \mathrm{L}^{-1}$ chlorate), the inhibition effect was enhanced by increasing the chlorate concentration. The perchlorate removal efficiencies within $6 \mathrm{~h}$ were $94 \%, 88 \%, 81 \%, 75 \%$ and $50 \%$ with $\mathrm{ClO}_{3}{ }^{-}$concentration rose from 20 to $100 \mathrm{mg} \mathrm{L}^{-1}$ (Fig. 3a), which indicated that perchlorate reduction was delayed even co-existing a small amount of chlorate $\left(20 \mathrm{mg} \mathrm{L}^{-1}\right)$. However, the specific perchlorate degradation rate was approximately $2.60 \mathrm{mg} \mathrm{ClO}_{4}^{-} \mathrm{g}_{-} \mathrm{VSS}^{-1} \mathrm{~h}^{-1}$ when the chlorate was completely removed (Fig. 3b). Nonetheless, the inhibitory effect on perchlorate reduction could not be explained from the thermodynamic perspective because the thermodynamics of chlorate reduction were lower than those of perchlorate reduction (Xu et al., 2015). It has been suggested by Nerenberg et al. (2006) that chlorate was preferentially reduced by (per)chlorate reductase in coexistence of perchlorate-chlorate. A similarly strong inhibitory effect of chlorate on perchlorate was reported by Dudley et al. (2008).

\subsubsection{Effect of nitrate on perchlorate reduction}

The experiment for the coexistence of perchlorate-nitrate is displayed in Fig. 4. The inhibition effect was enhanced as the nitrate concentration increasing. The perchlorate removal efficiencies within $6 \mathrm{~h}$ were $76 \%, 58 \%, 36 \%, 16 \%$ and $0 \%$ as $\mathrm{NO}_{3}{ }^{-}$concentration increased from 20 to $100 \mathrm{mg} \mathrm{L}^{-1}$ (Fig. 4a), which indicated that perchlorate reduction was delayed even co-existing a small amount of $\mathrm{NO}_{3}{ }^{-}\left(20 \mathrm{mg} \mathrm{L}^{-1}\right)$. However, this finding was contradictory with previous studies that PCRB utilized perchlorate in preference to nitrate (Bardiya and Bae, 2011; Oosterkamp et al., 2011; Xu et al., 2004). Xu et al. (2004) concluded that the perchlorate and nitrate was reduced by perchlorate reductase and nitrate reductase, respectively. Nevertheless, several studies suggested that perchlorate and nitrate were reduced by the same enzymes (Kotlarz et al., 2016; Zhu et al., 2016; London et al., 2011; Butler et al., 2010; Choi and Silverstein, 2008). Choi and Silverstein 
(2008) observed that the presence of nitrate caused a long lag in perchlorate reduction until nitrate had been completely reduced. Similar result was also found by Zhu et al. (2016). These indicated that perchlorate and nitrate were catalyzed by the same perchlorate reductase in PCRB.

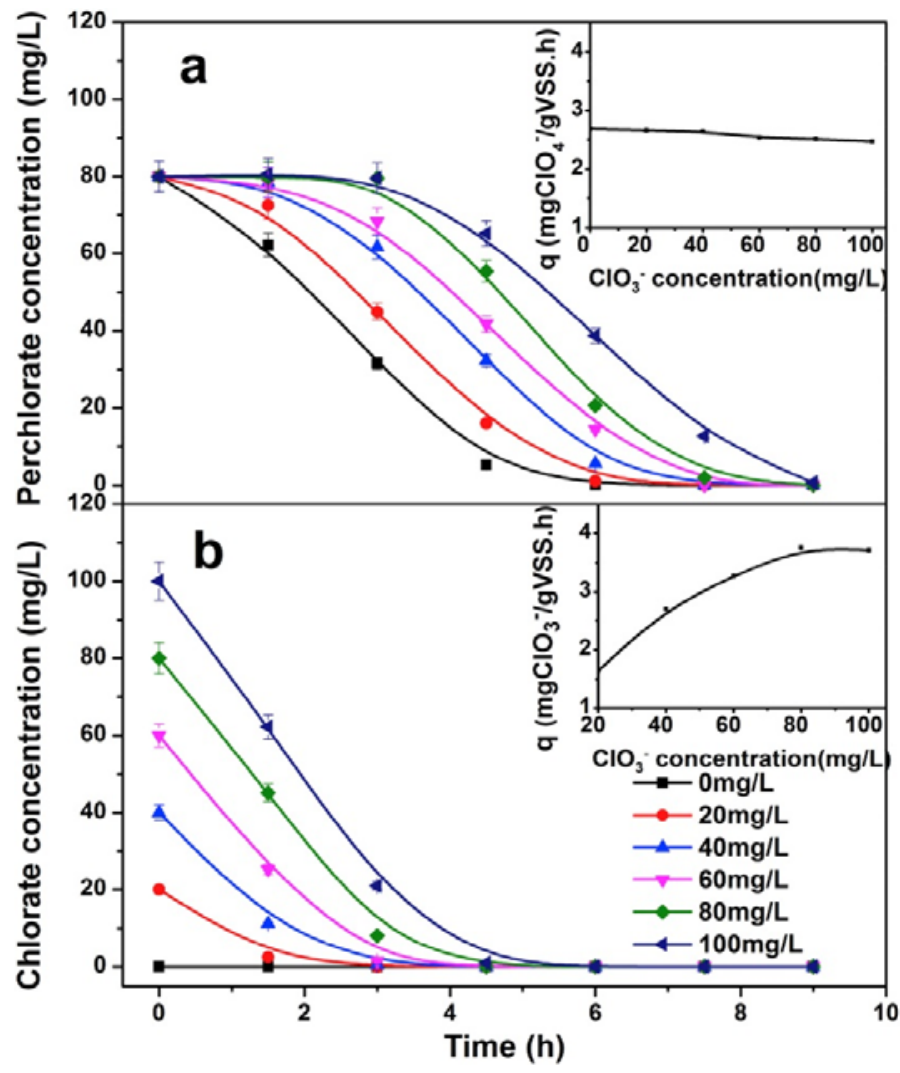

Fig. 3. Effect of different initial chlorate concentrations on perchlorate reduction. (a) the changes of perchlorate concentrations over time. (b) the changes of chlorate concentrations over time. (Conditions: biomass $=7.1 \pm 0.2 \mathrm{~g} \mathrm{VSS} \mathrm{L}^{-1}$; perchlorate concentration $=80 \mathrm{mg} / \mathrm{L}$; thiosulfate concentration $=200 \mathrm{mg} / \mathrm{L}$; temperature $=35^{\circ} \mathrm{C} ; \mathrm{pH}=7.0 \pm 0.2$ ).

\subsection{Effect of inhibitors on perchlorate reduction ETC}

Several studies have focused on the mechanism of T-driven perchlorate reduction ETC. The aim of this study was to explore the ETC of T-driven perchlorate reduction using six inhibitors.

$\mathrm{CuCl}_{2}$ and Rotenone are often used as an inhibitor of the NADH dehydrogenase (complex I) (Lian et al., 2016; Wang et al., 2016). $\mathrm{Cu}^{2+}$ was reported to be a Fe-S cluster inhibitor that blocks electron transfer to ubiquinone (Wang et al., 2016). Rotenone inhibited the NADH-ubiquinone reductase activity (Wang et al., 2016; Lian et al., 2016). The effect of $\mathrm{CuCl}_{2}$ (Fig. 5a) and Rotenone (Fig. 5b) revealed that the specific perchlorate degradation rate $\left(2.35 \mathrm{mg} \mathrm{ClO}_{4}^{-} \mathrm{g}-\mathrm{VSS}^{-1} \mathrm{~h}^{-1}\right)$ was similar at $\mathrm{Cu}^{2+}$ and Rotenone concentrations ranging from 0 to $400 \mu \mathrm{M} \mathrm{L}^{-1}$. In addition, the perchlorate removal efficiency was $100 \%$ within $6 \mathrm{~h}$ even at $\mathrm{Cu}^{2+}$ and Rotenone concentration of $400 \mu \mathrm{M} \mathrm{L}^{-1}$. This result indicated that complex I of the ETC might not be involved in the ETC of T-driven perchlorate reduction. 


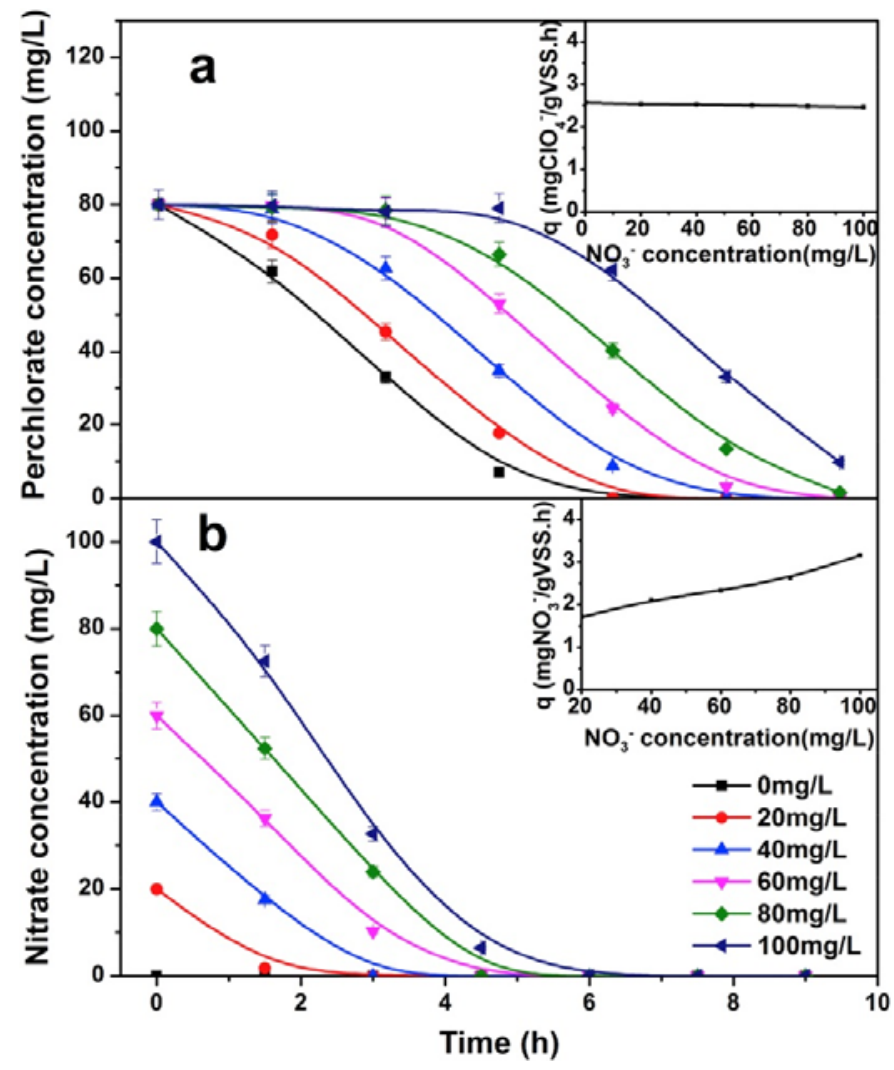

Fig. 4. Effect of different initial nitrate concentrations on perchlorate reduction. (a) the changes of perchlorate concentrations over time. (b) the changes of nitrate concentrations over time.

(Conditions: biomass $=7.1 \pm 0.2 \mathrm{~g} \mathrm{VSS} \mathrm{L}^{-1}$; perchlorate concentration $=80 \mathrm{mg} / \mathrm{L}$; thiosulfate concentration $=200 \mathrm{mg} / \mathrm{L}$; temperature $=35^{\circ} \mathrm{C} ; \mathrm{pH}=7.0 \pm 0.2$ ).

QDH inhibited FAD dehydrogenase (complex II) (Wang et al., 2016). The perchlorate removal efficiencies were $100 \%, 100 \%, 99 \%, 98 \%, 93 \%$ and $72 \%$ within $6 \mathrm{~h}$ at QDH concentrations of 0 , 20, 40, 100, 200 and $400 \mu \mathrm{M} \mathrm{L}^{-1}$, respectively. However, the perchlorate was completely reduced within $9 \mathrm{~h}$ (Fig. 5c). The result indicated that complex II participates in the ETC of T-driven perchlorate reduction. But complex II was not the only pathway for T-driven perchlorate reduction.

Dicumarol was often used as an inhibitor of the quinone loop (Wang et al., 2016; Woźnica et al., 2003). The perchlorate removal efficiencies were $95 \%$ and $70 \%$ at the concentrations of 200 and $400 \mu \mathrm{M} \mathrm{L}^{-1}$, respectively. Perchlorate was completely reduced within $9 \mathrm{~h}$ (Fig. 5d). The inhibition effect of dicumarol was similar to QDH. This result indicated that the electron was transport from complex II to the quinone loop, suggesting that the quinone loop participates in the ETC of Tdriven perchlorate reduction.

$\mathrm{NaN}_{3}$ inhibits cytochrome oxidase (complex IV) (Wang et al., 2016; Xi et al., 2013; Woźnica et al., 2003). The inhibition effect was enhanced by increasing the sodium azide concentration, and perchlorate reduction appeared to be almost completely inhibited at the sodium azide concentration of $400 \mu \mathrm{ML}^{-1}$ (Fig. 5e). The perchlorate removal efficiencies were $33 \%$ and $20 \%$ at the concentrations of 200 and $400 \mu \mathrm{M} \mathrm{L}^{-1}$, respectively. The result suggested that complex IV was the main pathway of ETC for T-driven perchlorate reduction. 

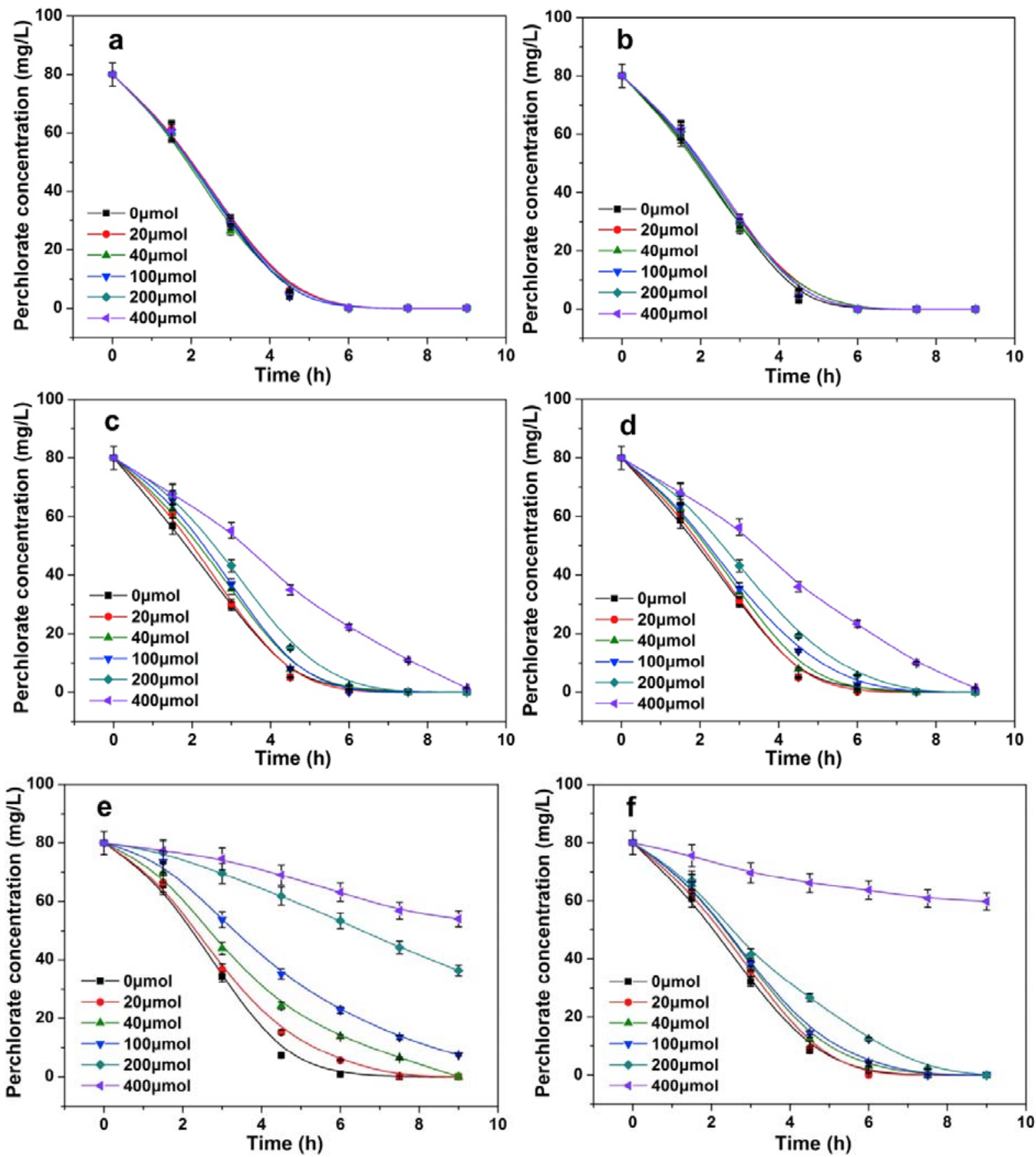

Fig. 5. Effect of inhibitors on perchlorate reduction. (a) $\mathrm{CuCl}_{2}$ (b) Rotenone (c) QDH (d) Dicumarol (e) $\mathrm{NaN}_{3}$ (f) DCCD. (Conditions: biomass $=7.1 \pm 0.2 \mathrm{~g} \mathrm{VSS} \mathrm{L}^{-1}$; perchlorate concentration $=80 \mathrm{mg} / \mathrm{L}$; thiosulfate concentration $=120 \mathrm{mg} / \mathrm{L}$; temperature $=35^{\circ} \mathrm{C}$;

$$
\mathrm{pH}=7.0 \pm 0.2) \text {. }
$$

DCCD inhibits ATP synthase, enabling it to diminish the product of ATP (Hunt et al., 2010). Perchlorate reduction appears to be completely inhibited at the DCCD concentration of $400 \mu \mathrm{M} \mathrm{L}^{-1}$ (Fig. 5f). The perchlorate removal efficiencies were 100\%, 100\%, 98\%, 97\%, 85\% and 20\% within $6 \mathrm{~h}$ at DCCD concentrations of $0,20,40,100,200$ and $400 \mu \mathrm{M} \mathrm{L}^{-1}$, respectively. Protons are a 
product of the oxidation of reduced sulfur compounds with the generation of a proton motive force that leads to ATP synthesis by ATPase (Madigan et al., 2011). DCCD blocks the proton channel and inhibits the activity of ATPase (Madigan et al., 2011). The distinct inhibition indicated that the T-driven perchlorate reduction process was needed for energy.

Madigan et al. (2011) reported that ETC consists of complex I, the quinone pool, complex II, complex III, cytochrome $c$ and complex IV. The ETC of T-driven perchlorate reduction was explored using different inhibitors that inhibited different sites in the perchlorate reduction process. Inhibitor experiments with Rotenone and $\mathrm{CuCl}_{2}$ demonstrated that complex I was not involved in the ETC. The perchlorate removal efficiency decreased at high QDH and dicumarol concentrations, which indicated that complex II and quinone loop participated in the ETC. The $\mathrm{NaN}_{3}$ experiment indicated that complex IV played an important role in the ETC. The inhibitor experiment with DCCD indicated that the T-driven perchlorate reduction process was needed for energy.

The inhibitors were also applied for chlorate reduction (Fig. S4). A similar inhibition function was found. The finding indicated that the T-driven PCRB could use a single enzyme, (per) chlorate reductase, to reduce perchlorate to chlorate and chlorate to chlorite. Similarly, a single enzyme was used for reducing perchlorate to chlorate and chlorate to chlorite had been reported by Xu et al. (2015).

$\mathrm{S}_{2} \mathrm{O}_{3}{ }^{2-}$ as an electron donor for bioremediation had been reported by Madigan et al. (2011). $\mathrm{S}_{2} \mathrm{O}_{3}{ }^{2-}$ is first split into $\mathrm{S}^{0}$ and $\mathrm{SO}_{3}{ }^{2-}$, both of which are eventually oxidized to $\mathrm{SO}_{4}{ }^{2-} . \mathrm{SO}_{3}{ }^{2-}$ is oxidized to $\mathrm{SO}_{4}{ }^{2-}$, and the electrons transfer to cytochrome $c$. Part of the $\mathrm{S}^{0}$ is reduced to $\mathrm{HS}^{-}$; then, the $\mathrm{HS}^{-}$is oxidized to $\mathrm{SO}_{4}{ }^{2-}$, and the electrons transfer to complex II. Most of the $\mathrm{S}^{0}$ and $\mathrm{S}_{2} \mathrm{O}_{3}{ }^{2-}$ provide electrons to cytochrome $c$.

A schematic of the ETC for T-driven perchlorate reduction (Fig. 6) had been set up based on this study and previous investigations (Lian et al., 2016; Wang et al., 2016; Xi et al., 2013; Madigan et al., 2011; Woźnica et al., 2003).

\subsection{Microbial community analysis}

The different microbial consortium structures of the original activated sludge, T-driven PCRB and S-driven PCRB were analyzed by $16 \mathrm{~S}$ DNA metagenomic sequencing. The bacterial sequences were further assigned to known phylum, order and genus (Fig. 7).

The phylum analysis results (Fig. 7a) indicated that the majority of the sequences belonged to Proteobacteria, Bacteroidetes, Chloroflexi, Firmicutes and Chlorobi. The proportions of Proteobacteria and Chloroflexi in T-driven PCRB were $35.81 \%$ and $36.30 \%$, respectively. Compared with the original activated sludge, the proportion of Proteobacteria declined from $50.05 \%$ to $35.81 \%$ while that of Chloroflexi increased from $8.82 \%$ to $36.30 \%$. However, the proportion of Proteobacteria was $83.00 \%$ in S-driven PCRB. Proteobacteria and Chloroflexi have been detected in perchlorate reduction and denitrification (Lian et al., 2016). At the order level, the majority of the sequences belonged to Anaerolineales, Campylobacterales, Clostridiales, Planctomycetales, Xanthomonadales, Sphingobacteriales, Syntrophobacterales, Burkholderiales, Rhodocyclales, Bacteroidales, Rhizobiales, Ignavibacteriales, Desulfobacterales and Rhodobacterales (ig. 7b). 
The sum of the 14 dominant order accounted for $52.65 \%$ (original activated sludge), $91.94 \%$ (Tdriven PCRB) and 79.13\% (S-driven PCRB) of the total sequences. This indicated the level of biodiversity decreased. Furthermore, Campylobacterales was found to be the largest order in Tdriven PCRB (34.99) and S-driven PCRB (64.96). Indicated here is the fact that both S-driven PCRB and T-driven PCRB had a similar higher consortium structure similarity compared to the original activated sludge.
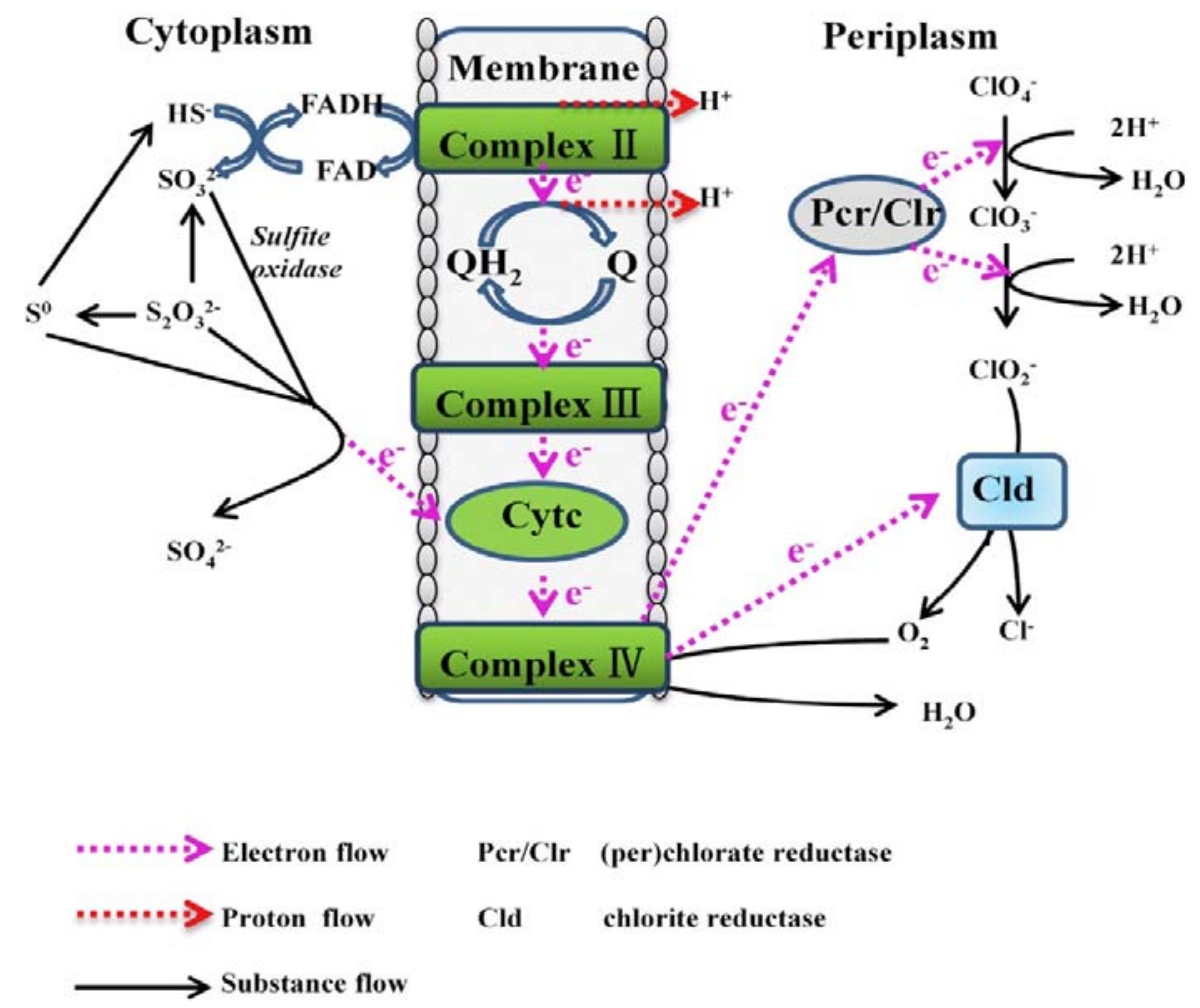

Fig. 6. The ETC of perchlorate reduction.

The genus level analyses provide a deeper understanding of the microbial consortium functions. The majority of the sequences belonged to Sulfurovum, Longilinea, Leptolinea, Ornatilinea, Smithella, Anaerolinea, Defluviimonas, and Ignavibacterium (Fig. 7c). Sulfurovum which can oxidize sulfur compounds coupled to the reduction of nitrate or perchlorate was the primary bacterium in T-driven PCRB (16.53\%) and S-driven PCRB (57.79\%) (Aranda et al., 2015; Inagaki et al., 2004). However, the proportion of Sulfurovum was only $6.04 \%$ in the original activated sludge (Fig. 7a). This outcome result indicated that Sulfurovum plays an important role in thiosulfate or sulfur oxidizing perchlorate reduction. Longilinea, Acinetobacter and Ignavibacterium were the most commonly reported sulfur-oxidizing autotrophic denitrifiers (Zhang et al., 2015; Bhaskaran et al., 2013). Since perchlorate and nitrate have similar redox potential, Longilinea, Acinetobacter and Ignavibacterium could reduce perchlorate and nitrate simultaneously using sulfur-oxidizing. 
(a) Bacterial Phylum

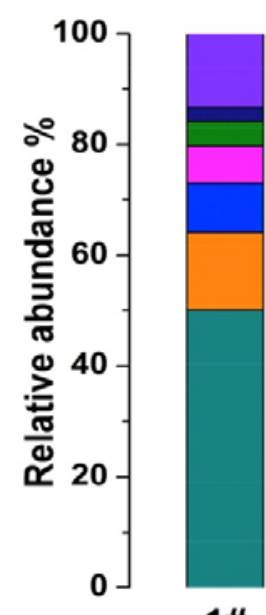

1\#

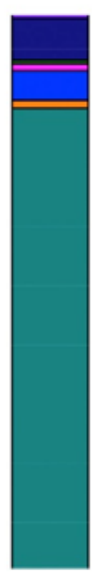

2\#

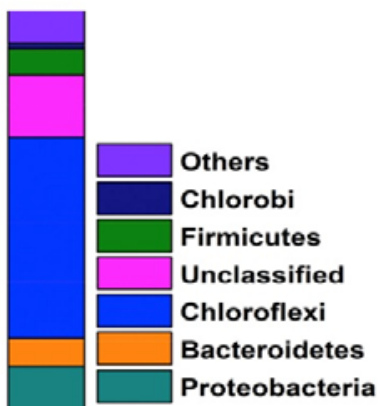

(b) Bacterial Order
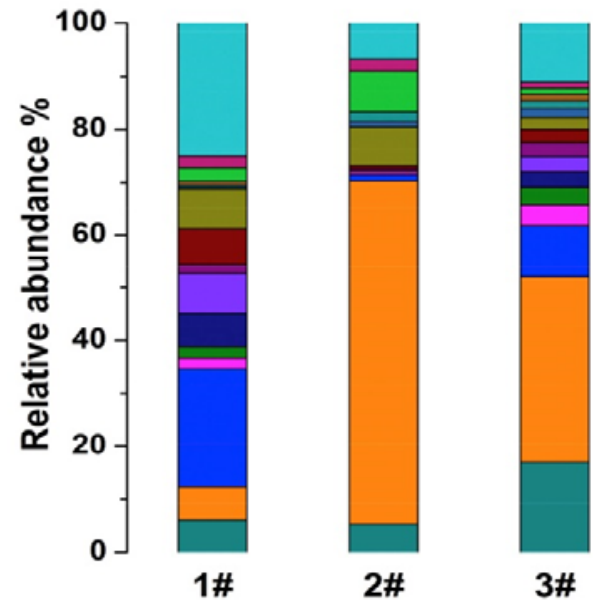

Others

Rhizobiales

Ignavibacteriales

Rhodobacterales

Desulfobacterales

Bacteroidales

Rhodocyclales

Burkholderiales

Syntrophobacterales

Sphingobacteriales

Xanthomonadales

Planctomycetales

Clostridiales

Unclassified

Campylobacterales

Anaerolineales

(c) Bacterial Genus

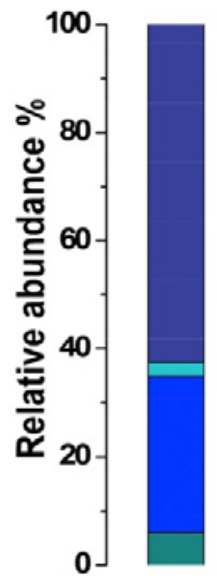

1\#

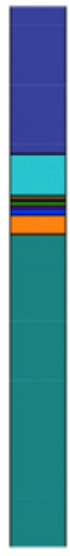

2\#

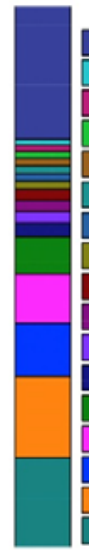

Others

Ignavibacterium

Defluviimonas

Unclassified Peptostreptococcaceae

Unclassified Porphyromonadaceae

Unclassified Saprospiraceae

Anaerolinea

Unclassified Lachnospiraceae

Smithella

Omatilinea

Unclassified Planctomycetaceae

Unclassified Xanthomonadaceae

Leptolinea

Longilinea

Unclassified

Unclassified Anaerolineaceae

Sulfurovum

3\#

Fig. 7. Taxonomic classification of the bacterial communities at (a) phylum, (b) order and (c) genus levels. Phylum, order and genus making up less than $1 \%$ of total composition in all samples were classified as "others". (1\# Original aerobic sludge; 2\# T-driven PCRB; 3\# Sdriven PCRB). 
For T-driven PCRB, the abundance of Longilinea, Acinetobacter and Ignavibacterium were 9.15\%, $1.43 \%$ and $1.12 \%$, respectively. Longilinea emerged as the most commonly reported PCRB (Wan et al., 2016), indicating that Longilinea, Acinetobacter and Ignavibacterium could oxidize thiosulfate coupled to the reduction of perchlorate. Leptolinea has been known to act as a dominant bacterial genus in sulfate reduction (Huang et al., 2015). Due to the presence of sulfate in T-driven and S-driven systems, the abundance of Leptolinea was $6.94 \%$ and $1.00 \%$ for T-driven PCRB and S-driven PCRB, respectively. The functions of those bacteria are summarized in Table S4. The results of this study provide important information for accelerating the start-up of a sulfur-based reactor by inoculating T-driven PCRB.

\section{Conclusions}

The mechanism of the ETC and the impacts of different influential factors on T-driven perchlorate reduction were investigated. The maximum perchlorate reduction efficiency was observed at $\mathrm{pH}$ 7.5 and $40^{\circ} \mathrm{C}$. The perchlorate kinetic parameters of the maximum specific degradation rate (qmax) were $3.70 \mathrm{mg} \mathrm{ClO}_{4}^{-} \mathrm{g}-\mathrm{VSS}^{-1} \mathrm{~h}^{-1}$, which was 0.54 -time of chlorate kinetic parameters. The process of perchlorate translated into chlorate was the rate limiting step. Perchlorate reduction was delayed in presence of $\mathrm{NO}_{3}{ }^{-}$and $\mathrm{ClO}_{3}{ }^{-}$. The mechanism of ETC further elucidated the $\mathrm{T}$-driven perchlorate reduction process. Biodiversity decreased greatly during the acclimation process. Sulfurovum which can oxidize sulfur compounds coupled to the reduction of nitrate or perchlorate was the primary bacterium in T-driven PCRB (16.53\%) and S-driven PCRB (57.79\%). This result provides important information for accelerating the start-up of a sulfur-based reactor by inoculating T-driven PCRB. Overall, this study creates a deeper understanding of the mechanism of T-driven perchlorate reduction.

\section{Acknowledgements}

This study was supported by the National Natural Science Foundation of China (Grant No. 51678387), Key project of Tianjin Natural Science Foundation (17JCZDJC39300) and the Science Research Program of High Level Talents in Hebei Universities (Grant No. GCC2014045, China.).

\section{Appendix A. Supplementary material}

Supplementary data related to this article can be found at http://dx.doi.org/10.1016/j.chemosphere.2017.07.039.

\section{References}

Anupama, V.N., Prajeesh, P.V., Anju, S., Priya, P., Krishnakumar, B., 2015. Diversity of bacteria, archaea and protozoa in a perchlorate treating bioreactor. Microbiol. Res. 177, 8-14.

APHA, 1998. Standard Methods for the Examination of Water and Wastewater, twentieth ed. American Public Health Association, Washington D.C.

Aranda, C.P., Valenzuela, C., Matamala, Y., Godoy, F.A., Aranda, N., 2015. Sulphurcycling bacteria and ciliated protozoans in a Beggiatoaceae mat covering organically enriched sediments beneath a salmon farm in a southern Chilean fjord. Mar. Pollut. Bull. 100, 270-278. 
Baidas, S., Gao, B., Meng, X., 2011. Perchlorate removal by quaternary amine modified reed. J. Hazard. Mater 189, 54-61.

Bardiya, N., Bae, J.H., 2011. Dissimilatory perchlorate reduction: a review. Microbiol. Res. 166, 237254.

Bhaskaran, K., Vijaya Nadaraja, A., Tumbath, S., Babu Shah, L., Gangadharan Puthiya Veetil, P., 2013. Phytoremediation of perchlorate by free floating macrophytes. J. Hazard. Mater 260, 901-906.

Boles, A.R., Conneely, T., McKeever, R., Nixon, P., Nusslein, K.R., Ergas, S.J., 2012. Performance of a pilot-scale packed bed reactor for perchlorate reduction using a sulfur oxidizing bacterial consortium. Biotechnol. Bioeng. 109, 637-646.

Butler, C.B., Clauwaert, P., Green, S.J., Verstraete, W., Nerenberg, R., 2010. Bioelectrochemical perchlorate reduction in a microbial fuel cell. Environ. Sci. Technol. 44, 4685-4691.

Choi, H., Silverstein, J., 2008. Inhibition of perchlorate reduction by nitrate in a fixed biofilm reactor. J. Hazard. Mater 159, 440-445.

Dudley, M., Salamone, A., Nerenberg, R., 2008. Kinetics of a chlorate-accumulating, perchloratereducing bacterium. Water. Res. 42, 2403-2410.

Gao, M., Wang, S., Ren, Y., Jin, C., She, Z., Zhao, Y., Yang, S., Guo, L., Zhang, J., Li, Z., 2016. Simultaneous removal of perchlorate and nitrate in a combined reactor of sulfur autotrophy and electrochemical hydrogen autotrophy. Chem. Eng. J. 284, 1008-1016.

Hong, Y., Xu, M., Guo, J., Xu, Z., Chen, X., Sun, G., 2007. Respiration and growth of Shewanella decolorationis S12 with an azo compound as the sole electron acceptor. Appl. Environ. Microbiol. 73, 4-72.

Huang, C., Li, Z., Chen, F., Liu, Q., Zhao, Y., Zhou, J., Wang, A., 2015. Microbial community structure and function in response to the shift of sulfide/nitrate loading ratio during the denitrifying sulfide removal process. Bioresour. Technol. 197, 227-234.

Hunt, K.A., Flynn, J.M., Naranjo, B., Shikhare, I.D., Gralnick, J.A., 2010. Substrate-level phosphorylation is the primary source of energy conservation during anaerobic respiration of Shewanella oneidensis strain MR-1. J. Bacteriol. 192, 3345-3351.

Inagaki, F., Takai, K., Nealson, K.H., Horikoshi, K., 2004. Sulfurovum lithotrophicum gen. nov., sp. nov., a novel sulfur-oxidizing chemolithoautotroph within the epsilon-Proteobacteria isolated from Okinawa Trough hydrothermal sediments. Int. J. Syst. Evol. Microbiol. 54, 1477-1482.

Ju, X., Field, J.A., Sierra-Alvarez, R., Salazar, M., Bentley, H., Bentley, R., 2007. Chemolithotrophic perchlorate reduction linked to the oxidation of elemental sulfur. Biotechnol. Bioeng. 96, 10731082.

Ju, X., Sierra-Alvarez, R., Field, J.A., Byrnes, D.J., Bentley, H., Bentley, R., 2008. Microbial perchlorate reduction with elemental sulfur and other inorganic electron donors. Chemosphere 71, 114-122.

Kotlarz, N., Upadhyaya, G., Togna, P., Raskin, L., 2016. Evaluation of electron donors for biological perchlorate removal highlights the importance of diverse perchlorate-reducing populations. Environ. Sci. Water Res. Technol. 2 (6), 1049-1063.

Lian, J., Tian, X., Guo, J., Guo, Y., Song, Y., Yue, L., Wang, Y., Liang, X., 2016. Effects of resazurin on perchlorate reduction and bioelectricity generation in microbial fuel cells and its catalysing mechanism. Biochem. Eng. J. 114, 164-172. 
Liebensteiner, M.G., Pinkse, M.W.H., Nijsse, B., Verhaert, P., Tsesmetzis, N., Stams, A.J.M., Lomans, B.P., 2015. Perchlorate and chlorate reduction by the Crenarchaeon Aeropyrum pernix and two thermophilic Firmicutes. Environ. Microbiol. Rep. 7 (6), 936-945.

London, M.R., De Long, S.K., Strahota, M.D., Katz, L.E., Speitel Jr., G.E., 2011. Autohydrogenotrophic perchlorate reduction kinetics of a microbial consortium in the presence and absence of nitrate. Water Res. 45 (19), 6593-6601.

Madigan, M.T., Martinko, J.M., Stahl, D.A., Clark, D.P., 2011. Brock Biology of Microorganisms, thirteenth ed. Benjamin Cummings, United States of America.

Mora, M., Dorado, A.D., Gamisans, X., Gabriel, D., 2015. Investigating the kinetics of autotrophic denitrification with thiosulfate: modeling the denitritation mechanisms and the effect of the acclimation of SO-NR cultures to nitrite. Chem. Eng. J. 262, 235-241.

Mora, M., L_opez, L.R., Gamisans, X., Gabriel, D., 2014. Coupling respirometry and titrimetry for the characterization of the biological activity of a SO-NR consortium. Chem. Eng. J. 251, 111-115.

Nerenberg, R., Kawagoshi, Y., Rittmann, B.E., 2006. Kinetics of a hydrogen-oxidizing, perchloratereducing bacterium. Water. Res. 40, 3290-3296.

Nerenberg, R., Kawagoshi, Y., Rittmann, B.E., 2008. Microbial ecology of a perchlorate-reducing, hydrogen-based membrane biofilm reactor. Water Res. 42 (4e5), 1151-1159.

Ontiveros-Valencia, A., Ilhan, Z.E., Kang, D.W., Rittmann, B., Krajmalnik-Brown, R., 2013. Phylogenetic analysis of nitrate- and sulfate-reducing bacteria in a hydrogen-fed biofilm. FEMS Microbiol. Ecol. 85 (1), 158-167.

Oosterkamp, M.J., Mehboob, F., Schraa, G., Plugge, C.M., Stams, A.J.M., 2011. Nitrate and (per) chlorate reduction pathways in (per) chlorate-reducing bacteria. Biochem. Soc. Trans. 39, 230-235.

Shi, Y., Zhang, P., Wang, Y., Shi, J., Cai, Y., Mou, S., Jiang, G., 2007. Perchlorate in sewage sludge, rice, bottled water and milk collected from different areas in China. Environ. Int. 33, 955-962.

Son, A., Lee, J., Chiu, P.C., Kim, B.J., Cha, D.K., 2006. Microbial reduction of perchlorate with zerovalent iron. Water Res. 40 (10), 2027-2032.

Song,W., Gao, B., Xu, X., Zhang, T., Liu, C., Tan, X., Sun, S., Yue, Q., 2015. Treatment of dissolved perchlorate by adsorptionemicrobial reduction. Chem. Eng. J. 279, 522-529.

Wan, D., Liu, Y., Niu, Z., Xiao, S., Li, D., 2016. Perchlorate reduction by hydrogen autotrophic bacteria and microbial community analysis using high-throughput sequencing. Biodegradation 27, 47-57.

Wang, S., Guo, J., Lian, J., Ngo, H.H., Guo, W., Liu, Y., Song, Y., 2016. Rapid start-up of the anammox process by denitrifying granular sludge and the mechanism of the anammox electron transport chain. Biochem. Eng. J. 115, 101-107.

Wang, Z., Gao, M., Zhang, Y., She, Z., Ren, Y., Wang, Z., Zhao, C., 2014. Perchlorate reduction by hydrogen autotrophic bacteria in a bioelectrochemical reactor. J. Environ. Manag. 142, 10-16.

Wo_znica, A., Dzirba, J., Ma_nka, D., Łabu_zek, S., 2003. Effects of electron transport inhibitors on iron reduction in Aeromonas hydrophila strain KB1. Anaerobe 9, 125-130.

Wu, D., He, P., Xu, X., Zhou, M., Zhang, Z., Houda, Z., 2008. The effect of various reaction parameters on bioremediation of perchlorate-contaminated water. J. Hazard. Mater 150, 419-423.

Xi, Z., Guo, J., Lian, J., Li, H., Zhao, L., Liu, X., Zhang, C., Yang, J., 2013. Study the catalyzing mechanism of dissolved redox mediators on bio-denitrification by metabolic inhibitors. Bioresour. Technol. 140, 22-27. 
Xu, J., Logan, B.E., 2003. Measurement of chlorite dismutase activities in perchlorate respiring bacteria. J. Microbiol. Methods 54, 239e247. Xu, J.L., Trimble, J.J., Steinberg, L., Logan, B.E., 2004. Chlorate and nitrate reduction pathways are separately induced in the perchlorate-respiring bacterium Dechlorosoma sp KJ and the chlorate-respiring bacterium Pseudomonas sp PDA. Water Res. 38, 673-680.

Xu, X., Gao, B., Jin, B., Zhen, H., Wang, X., Dai, M., 2015. Study of microbial perchlorate reduction: considering of multiple $\mathrm{pH}$, electron acceptors and donors. J. Hazard. Mater 285, 228-235.

Ye, L., You, H., Yao, J., Kang, X., Tang, L., 2013. Seasonal variation and factors influencing perchlorate in water, snow, soil and corns in Northeastern China. Chemosphere 90, 2493-2498.

Zhang, L., Zhang, C., Hu, C., Liu, H., Bai, Y., Qu, J., 2015. Sulfur-based mixotrophic denitrification corresponding to different electron donors and microbial profiling in anoxic fluidized-bed membrane bioreactors. Water. Res. 85, 422-431.

Zhao, H.P., Van Ginkel, S., Tang, Y., Kang, D.W., Rittmann, B., Krajmalnik-Brown, R., 2011. Interactions between perchlorate and nitrate reductions in the biofilm of a hydrogen-based membrane biofilm reactor. Environ. Sci. Technol. 45, 10155-10162.

Zhu, Y., Gao, N., Chu, W., Wang, S., Xu, J., 2016. Bacterial reduction of highly concentrated perchlorate: kinetics and influence of co-existing electron acceptors, temperature, $\mathrm{pH}$ and electron donors. Chemosphere 148, 188-194. 